\title{
Growth of Ultralong Ag Nanowires by Electroless Deposition in Hot Ethylene Glycol for Flexible Transparent Conducting Electrodes
}

\author{
Nathaniel de Guzman and Mary Donnabelle L. Balela \\ Sustainable Electronic Materials Group, Department of Mining, Metallurgical and Materials Engineering, \\ University of the Philippines, 1101 Diliman, Quezon City, Philippines \\ Correspondence should be addressed to Mary Donnabelle L. Balela; mlbalelal@up.edu.ph
}

Received 21 February 2017; Revised 4 May 2017; Accepted 8 June 2017; Published 18 July 2017

Academic Editor: Thierry Baron

Copyright (C) 2017 Nathaniel de Guzman and Mary Donnabelle L. Balela. This is an open access article distributed under the Creative Commons Attribution License, which permits unrestricted use, distribution, and reproduction in any medium, provided the original work is properly cited.

High aspect ratio silver $(\mathrm{Ag})$ nanowires with an average length of $25.4 \mu \mathrm{m}$ and diameter of $102.8 \mathrm{~nm}$ were successfully prepared by electroless deposition in hot ethylene glycol $\left(160^{\circ} \mathrm{C}\right)$ for $1 \mathrm{~h}$ in the presence of PVP. It was found that both PVP concentration and molecular weight significantly influence the morphology and yield of Ag nanowires in solution. Using PVP MW = 55,000, addition of lower amounts of PVP led to formation of large irregularly shaped Ag particles together with a few rod-like structures. Increasing PVP concentration generally resulted in longer and thinner Ag nanowires. On the other hand, low molecular weight PVP produced spherical Ag particles even at high PVP concentration. Ag nanowire flexible transparent conducting electrodes attained a sheet resistance of about $92.5 \Omega / \mathrm{sq}$ at an optical transmittance of about $79.6 \%$ without any heat treatment. In addition, no significant change in optical and electrical properties was observed after several cycles of bending and adhesion test.

\section{Introduction}

Due to the recent advances in technology, materials with high optical transparency and excellent electrical conductivity are being extensively used for many modern optoelectronic devices such as flat-panel televisions, e-readers, smart-phones, smart-glass, liquid crystal displays (LCDs), organic light emitting diodes (OLEDs), solar cells, and touch panel displays $[1,2]$. Transparent electrodes (TEs), the main component of these devices, can extract electrons from the active layer while allowing light to enter through the device [3-6]. In the last decade, the number of electronic displays and touch screens has increased drastically.

Transparent conducting oxides (TCOs), such as aluminumdoped tin oxide [3], fluorine-doped tin oxide [4], and zinc oxide [5], are currently used for these kinds of applications. In particular, indium tin oxide (ITO) is the most widely used because of its low sheet resistance and high optical transmittance $[6,7]$. TCOs are transparent due to their large bandgaps $(>3 \mathrm{eV})$, with energy values greater than that of visible light. Thus, phonons with energies below the bandgap are not absorbed by these materials [8] and visible light can pass through which translates to the transparency of the material $(>90 \%$ at $550 \mathrm{~nm})$. On the other hand, the low sheet resistance $(<1000 \Omega / \mathrm{sq})$ is due to the high doping concentration of metals such as $\mathrm{Al}$ and In [9]. However, several drawbacks limit the utilization of ITO in future optoelectronic devices. One is the scarcity of In in the Earth's crust $(0.05 \mathrm{ppm})$, leading to escalating prices [10]. The fabrication of ITO film is also inefficient. For example, during sputtering process, most of the ITO material is sputtered on the walls of the chamber. Moreover, the brittle nature of ITO makes it unsuitable for flexible electronic devices. An applied strain as little as $2-3 \%$ can initiate brittle fracture on the ITO film when coated on flexible substrates [10].

Currently, organic materials like graphene [11-13], carbon nanotubes [14-18], and conducting polymers [19] as well as inorganic materials like metal grids [20] and nanowires [2125] are being explored to replace ITO. Organic materials have the advantages of low-cost processing, mechanical flexibility, 
and ease of fabrication compared to inorganic materials [11]. However, their performance is still inferior to ITO. Silver $(\mathrm{Ag})$ and copper $(\mathrm{Cu})$ nanowire thin films have been reported to achieve electrical and optical properties comparable to ITO thin films [21-26]. Then again, Cu oxidizes easily, which increases its sheet resistance [22, 23].

Ag nanowires are considered by some to be the best material to replace ITO [25-28]. Ag exhibits excellent malleability, oxidation-stability, and mechanical robustness. It also has the highest bulk electrical conductivity among all metals $(6.3 \times$ $10^{7} \mathrm{~S} / \mathrm{cm}$ ) [21]. Though Ag is a precious metal (approximately $\$ 570$ per $\mathrm{kg}$ ), a large concentration of $\mathrm{Ag}$ nanowires can be synthesized at low temperature in a single process [26]. Ag nanowire inks can also be printed on different substrates at temperatures lower than the physical deposition temperature of metal oxides [27, 28]. In addition, several studies have demonstrated that a transparent electrode with a sheet resistance of $<100 \Omega /$ sq at an optical transmittance $>80 \%$ can be achieved easily from solution-synthesized Ag nanowires $[29,30]$.

In this study, ultralong Ag nanowires with diameters in the range of $80-120 \mathrm{~nm}$ and lengths up to $10-50 \mu \mathrm{m}$ are successfully prepared by electroless deposition (reduction) in hot ethylene glycol (EG) at $160^{\circ} \mathrm{C}$ (polyol method). Most studies have reported the use of exotic and expensive seeds (e.g., $\mathrm{Pt}$ and $\mathrm{Au}$ ) and salts (e.g., $\mathrm{CuCl}_{2}$ and $\mathrm{NaCl}$ ) in order to promote the growth of ultralong nanowires $(>20 \mu \mathrm{m})[28-$ 30]. Long and thin nanowires are vital to obtain transparent electrodes with low resistance and high optical transparency at a low Ag nanowire density [30]. To the best of our knowledge, the Ag nanowires produced in this study are significantly longer than the reported Ag nanowires prepared by a single-step polyol process without the use the expensive exotic seeds and salts [28-32].

This work also presents a comprehensive study of the effects of various solution parameters, such as PVP molecular weight and concentration, reaction time, and temperature on the dimension and yield of Ag nanowires. A formation mechanism for the growth of Ag nanowires is then proposed. Additionally, Ag nanowires flexible transparent conducting electrodes were fabricated by rod coating without any harsh posttreatment, that is, annealing and pressing. The optical, electrical, and mechanical properties of the $\mathrm{Ag}$ nanowire transparent conducting electrodes are then investigated.

\section{Methodology}

2.1. Electroless Deposition of Ag Nanowires in Hot Ethylene Glycol. Silver nitrate $\left(\mathrm{AgNO}_{3}, \mathrm{RTC}\right)$ was used as the $\mathrm{Ag}(\mathrm{I})$ precursor. Ethylene glycol (EG, J. T. Baker) was used as both solvent and reducing agent. Polyvinyl pyrrolidone (PVP, Sigma-Aldrich) with increasing molecular weights of $10,000,55,000$, and 360,000 was employed as protective and structure-directing agent. The calculation of the molar ratio was based on the molecular weight $(111 \mathrm{~g} / \mathrm{mol})$ of the repeating unit of PVP. In a typical experiment, $10 \mathrm{~mL}$ of ethylene glycol was heated in a three-neck flask in an oil bath at $160^{\circ} \mathrm{C}$ for $1 \mathrm{~h}$ with reflux. Then, $3 \mathrm{~mL}$ of $0.1 \mathrm{M} \mathrm{AgNO}_{3}-$ EG solution was gradually injected into the hot ethylene glycol solution for about $10 \mathrm{~min}$. Simultaneously, an equal volume $(3 \mathrm{~mL})$ of $0.1 \mathrm{M}$ PVP-EG solution was introduced into the hot ethylene glycol solution. The total solution was then stirred at a rate of $260 \mathrm{rpm}$ throughout the reaction and allowed to continue for $1 \mathrm{~h}$. The Ag products were collected by centrifugation at $3000 \mathrm{rpm}$ for $20 \mathrm{~min}$ and washed with ethanol. This washing process was repeated 3 times to remove excess ethylene glycol and PVP. The Ag nanowires were then stored in ethanol.

The morphology of the metal nanowires was examined under scanning electron microscope (SEM, JEOL 5300) and high-resolution transmission electron microscope (HRTEM, JEOL JEM-ARM200F). The dimensions (length and diameter) of the Ag nanowires were determined by measuring more than 200 nanowires from several SEM images using ImageJ software. The percent yield of the Ag nanowires was obtained by estimating the area covered by these nanowires relative to the total area of all nanostructures (nanowires and nanoparticles). Moreover, selected area electron diffraction (SAED) was coupled with HRTEM to determine the growth direction and crystallographic planes of the nanowires. Compositional and structural analysis was performed using X-ray diffraction (XRD, $\mathrm{Cu} \mathrm{K} \alpha$, Shimadzu XRD-7000) and Fourier Transform Infrared Spectroscopy (FTIR).

2.2. Fabrication of Ag Nanowire Flexible Transparent Conducting Electrode. Solution-synthesized Ag nanowires were dispersed in ethanol or an organic ink formulation before deposition on polymer substrates by Meyer rod coating. Before mixing with ethanol, the Ag nanowires were thoroughly washed in $40 \mathrm{ml}$ of ethanol and then followed by mixing vigorously. The solution was then sonicated for $30 \mathrm{~s}$ to further disperse the nanowires in the solution. Afterwards, the suspension was centrifuged at $3000 \mathrm{rpm}$ for $20 \mathrm{~min}$. The supernatant was carefully decanted, and the residual precipitate was dispersed in ethanol and prepared for further washing. The washing and centrifugation cycle was repeated for 5 times. On the other hand, cellulose acetate substrates were sonicated for $10 \mathrm{~min}$ in acetone then in isopropyl alcohol (RTC) to remove grease and small particles on the surface. Afterwards, the substrates were dried under nitrogen $\left(\mathrm{N}_{2}\right)$ gas. For rod coating, a Meyer rod (\#10, RD Specialist) was used.

The sheet resistance and visible transmittance of the Ag nanowire transparent conducting electrodes were measured using four-point probe (Jandell) and UV-Vis spectrophotometer (Agilent Tech.), respectively. The mechanical properties of the electrodes were tested by bending the polymer electrodes at a $90^{\circ}$ curvature for 100 cycles. The change in resistance $\left(R / R_{o}\right)$ was measured every cycle. Lastly, tape test was employed using a $3 \mathrm{M}$ scotch tape to determine if the coated nanowires have good adhesion on the substrates.

\section{Results and Discussion}

3.1. Effect of PVP Concentration on the Formation of $A g$ Nanowires. Figure 1 shows the SEM images of Ag products prepared by electroless deposition in hot ethylene glycol $\left(160^{\circ} \mathrm{C}\right)$ using PVP $\mathrm{MW}=55,000$ at increasing PVP to $\mathrm{AgNO}_{3}$ 


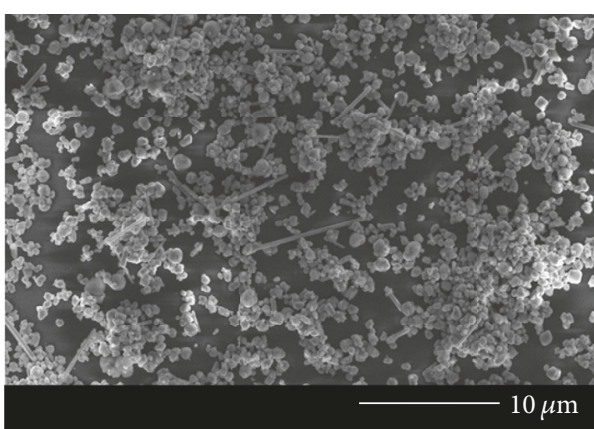

(a)

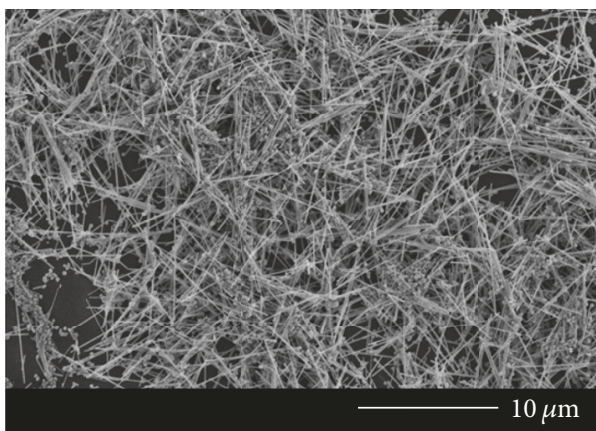

(b)

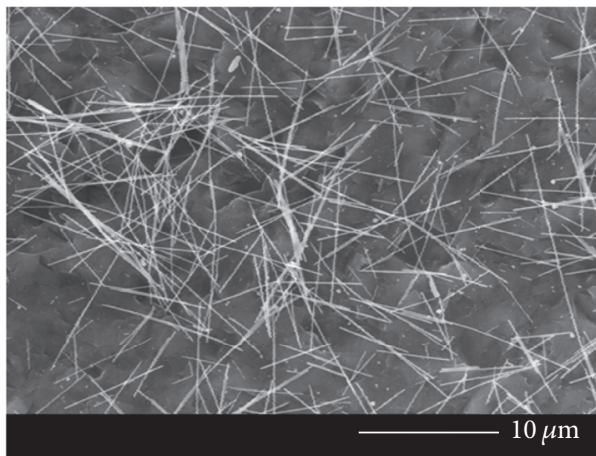

(c)

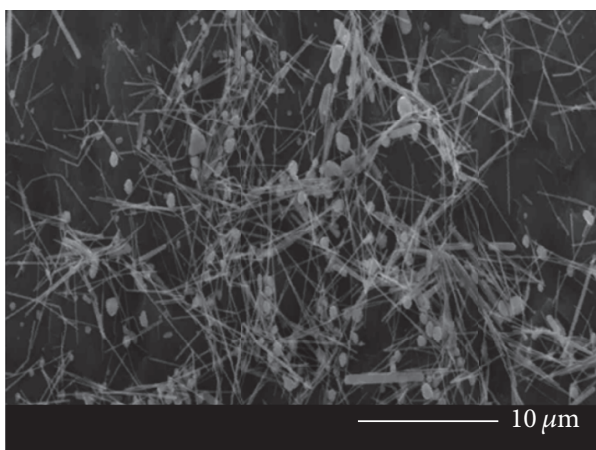

(d)

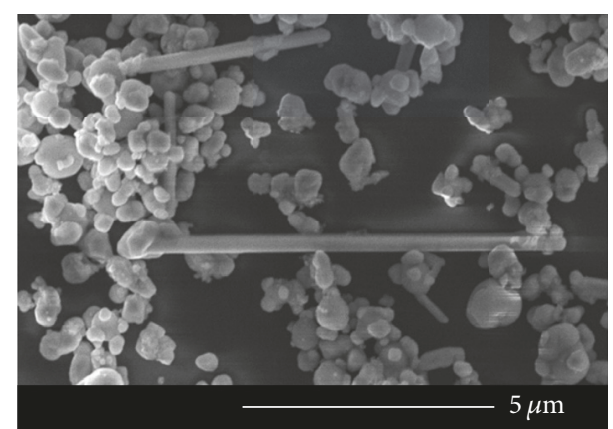

(a) $\mathrm{i}$

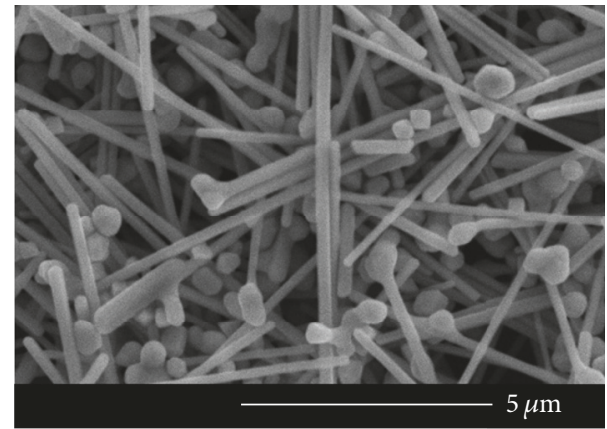

(b)i

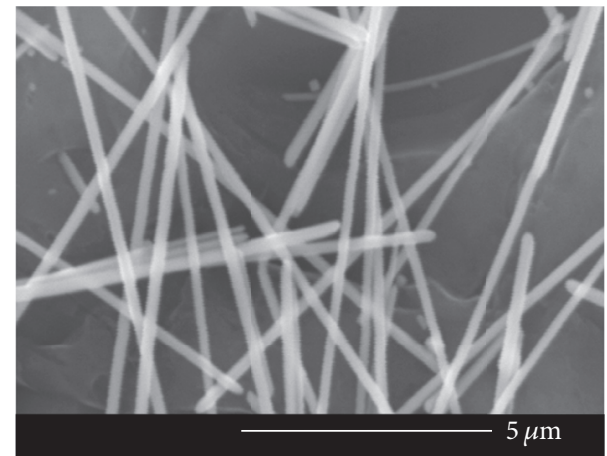

(c) $\mathrm{i}$

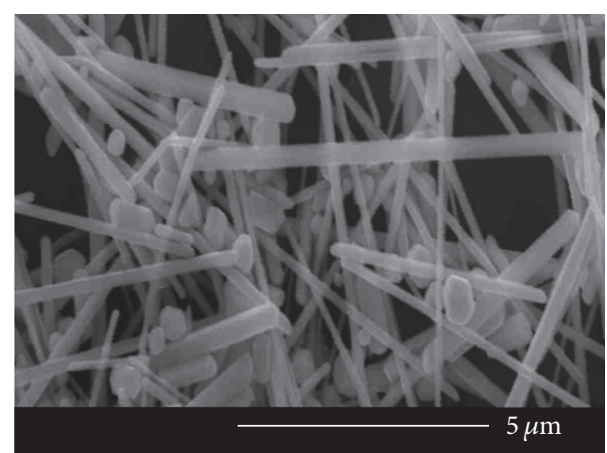

(d)i

FIGURE 1: SEM images of the Ag products formed by electroless deposition in hot ethylene glycol $\left(160^{\circ} \mathrm{C}\right)$ using increasing PVP MW $=55,000$ to $\mathrm{AgNO}_{3}$ molar ratio of (a) 1, (b) 2, (c) 3, and (d) 6. Images labeled (i) are corresponding images taken at higher magnification.

molar ratio. As seen in Figure 1(a), Ag particles along with a few rod-like structures were formed at a low PVP to $\mathrm{AgNO}_{3}$ molar ratio of 1 . The large Ag particles were irregularly shaped and nonuniform in size with a mean diameter of about $175.6 \mathrm{~nm}$. On the other hand, the short rod-like structures had a mean diameter and length of about $134.5 \mathrm{~nm}$ and $3.5 \mu \mathrm{m}$, respectively. Increasing the molar ratio to 2 resulted in the formation of $\mathrm{Ag}$ nanowires with mean length and diameter of about $14.7 \mu \mathrm{m}$ and $93.1 \mathrm{~nm}$, respectively (Figure $1(\mathrm{~b})$ ). However, Ag particles, having an average size of $153.5 \mathrm{~nm}$, 


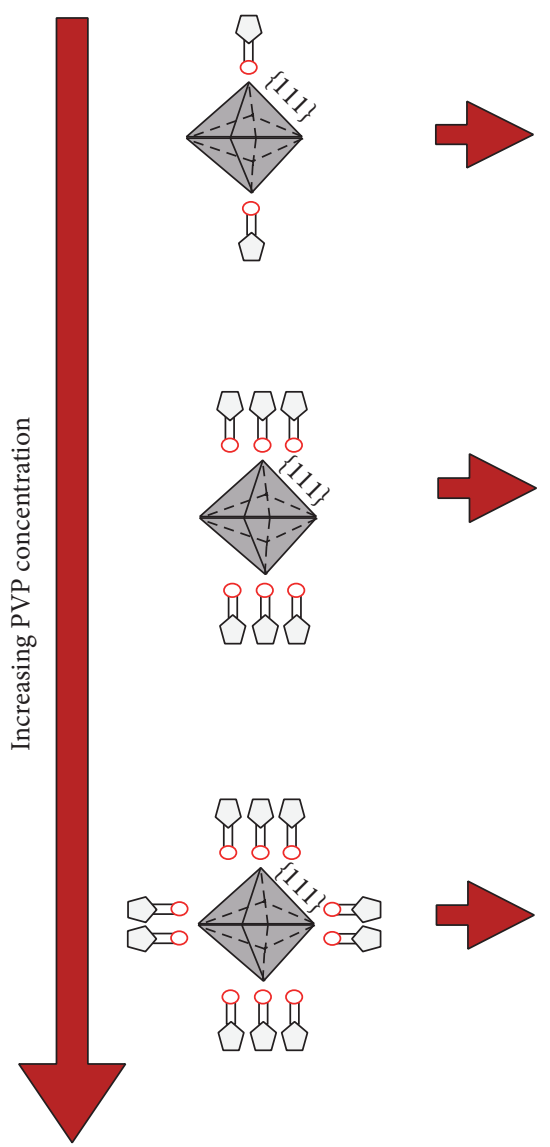

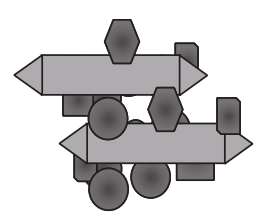

Particles and rods

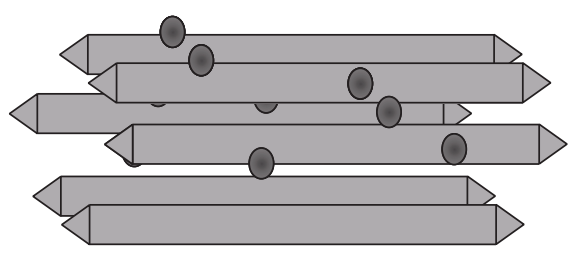

Nanoparticles and nanowires

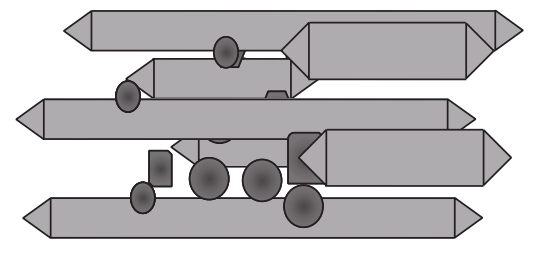

Particles, rods, nanowires

FIGURE 2: Schematic illustration of the effect of increasing PVP concentration on the growth of multiply-twinned Ag nuclei and the final morphology of the Ag products.

were still produced together with the nanowires. The Ag nanowire yield was approximated to be about $50 \%$ when PVP to $\mathrm{AgNO}_{3}$ molar ratio of 2 was used.

At a PVP molar ratio of $3, \mathrm{Ag}$ nanowires with an aspect ratio of 250 were generated as shown in Figure 1(c). The Ag nanowires have an average length of $25.4 \mu \mathrm{m}$ and a mean diameter of about $102.8 \mathrm{~nm}$. This is about $70 \%$ increase in length compared to the Ag nanowires prepared at a PVP molar ratio of 2 . In addition, there was an apparent decrease in the number and diameter (mean diameter of about $115.3 \mathrm{~nm}$ ) of Ag nanoparticles formed with the nanowires. The nanowire yield was estimated to be about $95 \%$. However, shorter and thicker Ag nanowires were produced when the amount of PVP was further increased to 6 (PVP to Ag molar ratio). The average length was reduced to $15.6 \mu \mathrm{m}$, while the average diameter was enlarged from 102.8 to $167.3 \mathrm{~nm}$ as seen in Figure 1(d). In addition, the concentration of Ag particles (mean diameter of about $235 \mathrm{~nm}$ ) mixed with nanowires was also increased.

It is apparent from the SEM images in Figure 1 that the amount of PVP in the solution is crucial in the formation of Ag nanowires. When PVP concentration was not sufficient (PVP: $\mathrm{AgNO}_{3}=1$ ), $\mathrm{Ag}$ nanowires were not produced. It is possible that the multiply-twinned Ag crystals initially formed during the early stage of the reaction agglomerated due to low concentration of PVP [29, 30, 33-35]. This could have led to the large irregular Ag particles as illustrated in the schematic in Figure 2. Additionally, it has been reported that PVP influences the growth rate of crystallographic planes of Ag nuclei in solution [29, 30, 34, 36, 37]. For face-centered cubic (fcc) metals such as Ag, the $\{111\}$ facets are considerably denser than $\{100\}[29,30,34,36,37]$. Thus, PVP preferentially adheres on $\{100\}$, effectively passivating these facets $[29,30$, $34,36,37]$. When the concentration of PVP is sufficient (PVP: $\mathrm{AgNO}_{3}=2$ ), PVP possibly shields the $\{100\}$ facets from the $\mathrm{Ag}$ atoms, slowing down the deposition of $\mathrm{Ag}^{0}$ on these planes. Consequently, Ag deposition occurs faster on $\{111\}$, which promotes anisotropic growth. Increasing the concentration further (PVP: $\mathrm{AgNO}_{3}=3$ ) leads to more PVP molecules attaching on the $\{100\}$ planes, which results in the formation of relatively longer Ag nanowires [29, 30]. Excess concentration of PVP, however, possibly leads to attachment of PVP molecules even on the $\{111\}$ planes [38-40]. Thus, shorter and thicker Ag nanowires were formed together with particles.

Figure 3 shows the XRD patterns of Ag particles and nanowires prepared by electroless deposition in hot ethylene glycol at increasing amount of PVP 55,000. The peaks at 38.32, $45.10,64.45$, and $77.68^{\circ}$ are the reflections of the (111), (200), (220), and (311) planes of Ag (JCPDS file number 04-0783). 


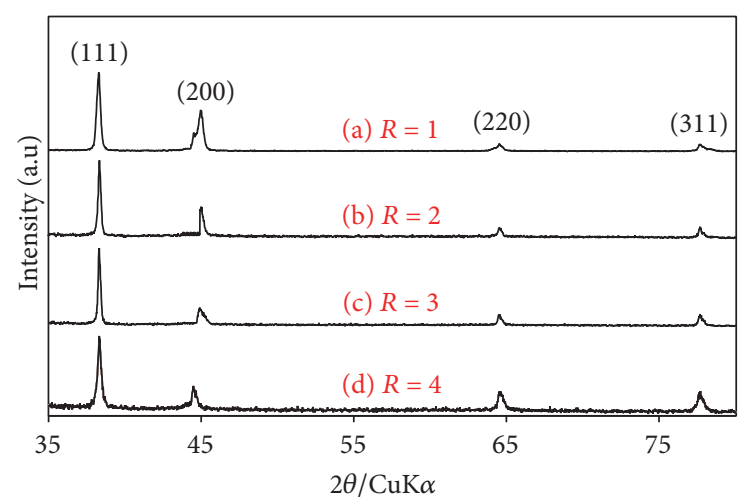

FIGURE 3: XRD pattern of Ag products formed by electroless deposition in hot ethylene glycol $\left(160^{\circ} \mathrm{C}\right)$ using increasing PVP MW $=55,000$ to $\mathrm{AgNO}_{3}$ molar ratio of (a) 1, (b) 2, (c) 3, and (d) 6 .

No other peaks were identified, suggesting absence of any impurities. In addition, the strong intensity of the XRD peaks indicates high crystallinity of the Ag products. The intensity ratio of the (111) and (200) peaks of fcc Ag from the JCPDS file is about 2.5 for PVP to Ag molar ratio of 2 to 3 ; the intensity ratio between the (111) and (200) peaks was increased from 2.63 to 3.95. However, when the PVP to Ag molar ratio was 6 , an intensity ratio of 2.56 was observed maybe due to the emergence of large particles along with nanowires as seen in Figure 1(d). The increase in the intensity ratio relative to the standard value can be attributed to the increase in both yield and length of Ag nanowires in the samples. During nanowire growth, deposition of Ag atoms occurs on the $\{111\}$ facets. This promotes growth of these facets, which could lead to an increase in the intensity of the (111) peaks in the XRD patterns [38-40].

\subsection{Effect of PVP Molecular Weight on the Formation of $A g$} Nanowires. Figure 4 shows the SEM images of Ag products prepared by electroless deposition in hot ethylene glycol $\left(160^{\circ} \mathrm{C}\right)$ with increasing PVP molecular weight at a constant PVP to $\mathrm{AgNO}_{3}$ molar ratio of 3 . When a low molecular weight PVP was used $(\mathrm{MW}=10,000)$, mostly irregular particles were prepared. For example, for a PVP molar ratio of 3, Ag particles with a mean diameter of $435 \mathrm{~nm}$ were produced as in Figure 4(a). On the other hand, mostly Ag nanowires were formed with PVP MW $=55,000$ with an average length of $25.4 \mu \mathrm{m}$ and average diameter of about $102.8 \mathrm{~nm}$ (Figure 4(b)). At PVP MW = 360,000, relatively thicker and shorter nanowires were produced compared to PVP MW = 55,000 as seen in Figure 4(c). The nanowires produced using PVP MW $=360,000$ have an average length and diameter of $20.1 \mu \mathrm{m}$ and $135.7 \mathrm{~nm}$, respectively. Moreover, some large particles and rods were also present in the solution.

It has been reported that PVP molecules easily coordinate with metal ions and atoms through its carbonyl groups $(\mathrm{C}=\mathrm{O})$ $[29,30,34,36-40]$. PVP with a high molecular weight has a higher degree of polymerization and thus has a higher average number of repeating units, $N$ [38-40]. In effect, there are more carbonyl groups $(\mathrm{C}=\mathrm{O})$ available at higher molecular weight PVP. Therefore, it is possible that the multiply-twinned Ag structures formed during nucleation grew equally in all crystallographic directions due to the lack of steric hindrance provided by low molecular weight PVP $\mathrm{MW}=10,000$. In addition, agglomeration of the Ag nuclei was probably not prevented. This resulted in the large $\mathrm{Ag}$ particles in Figure 4(a). However, when the molecular weight was very high (MW $=360,000)$, the fast growing ends $\{111\}$ were also covered by PVP leading to the formation of shorter and thicker nanowires.

3.3. Effect of Temperature on the Formation of Ag Nanowires. Figure 5 is the SEM images of the Ag nanostructures synthesized by electroless deposition in hot ethylene glycol at increasing temperature. At $120^{\circ} \mathrm{C}$, only micrometer-sized irregular Ag particles with a mean diameter of $177.3 \mathrm{~nm}$ were formed, as seen in Figure 5(a). On the other hand, $\mathrm{Ag}$ nanowires with mean diameter of about $115.3 \mathrm{~nm}$ were produced when the temperature was increased to $160^{\circ} \mathrm{C}$. The nanowires have an average length of $25.4 \mu \mathrm{m}$ (Figure 5(b)). At even higher temperature of $180^{\circ} \mathrm{C}$, significantly shorter and thicker Ag nanowires with an average length and diameter of about $18.5 \mu \mathrm{m}$ and $136.4 \mathrm{~nm}$, respectively, were formed in the solution as seen in Figure 5(c).

When heat is introduced into the solution, ethylene glycol is oxidized to glycolaldehyde as given by (1). The rate of formation of glycolaldehyde, the true reducing agent of $\mathrm{Ag}^{+}$ ions (2), increases with increasing temperature [41, 42]. As more glycolaldehyde is produced, the reducing power of the solvent is enhanced.

$$
\begin{aligned}
\mathrm{HOCH}_{2} \mathrm{CH}_{2} \mathrm{OH} \longrightarrow & \mathrm{CH}_{3} \mathrm{CHO}+\mathrm{H}_{2} \mathrm{O} \\
2 \mathrm{Ag}^{+}+2 \mathrm{CH}_{3} \mathrm{CHO} \longrightarrow & \mathrm{CH}_{3} \mathrm{CO}-\mathrm{OCCH}_{3}+2 \mathrm{Ag} \\
& +2 \mathrm{H}^{+}
\end{aligned}
$$

At a relatively low temperature $\left(120^{\circ} \mathrm{C}\right)$, the reduction rate of $\mathrm{Ag}^{+}$ions, as well as the nucleation of $\mathrm{Ag}$ crystals, is slow. In addition, the probability of Ag nuclei having a multiplytwinned structure is reduced due to the high thermal energy required for the formation of twins [43]. Thus, it is possible that only few Ag nuclei were precipitated in the solution at a time due to the slow reduction rate. More Ag atoms were then available during growth period, which explains their large particle size. Further, the difficulty in forming a multiplytwinned structure at relative low temperature hindered the anisotropic growth of the Ag nuclei. It is presumed that the particles grew from single cuboctahedral crystals, which lead to their irregular shape instead of the formation of nanowires [38-40].

On the other hand, when the reaction temperature was increased to $160^{\circ} \mathrm{C}, \mathrm{Ag}^{+}$ions were reduced immediately after injection of the $\mathrm{Ag}$ precursor to produce a large number of nuclei. At this temperature, the formation of multiplytwinned Ag nuclei was favoured, which eventually grew to high aspect ratio $\mathrm{Ag}$ nanowires $[29,30,34,36-40]$. At $180^{\circ} \mathrm{C}$, more multiply-twinned particles were precipitated during nucleation stage, which limits the concentration of Ag atoms available for the growth of nanowires. As a result, low aspect ratio Ag nanowires were produced [29, 30, 34, 36-40]. 


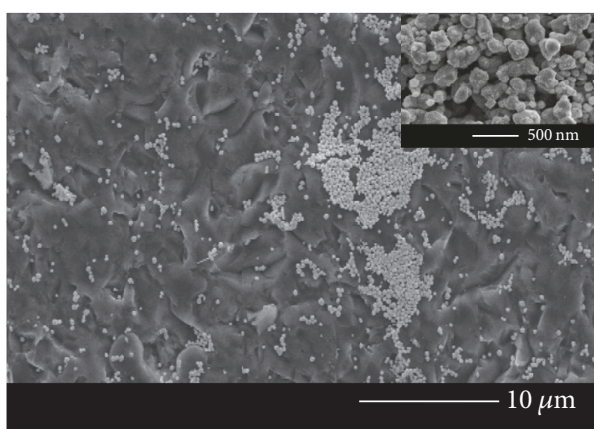

(a)

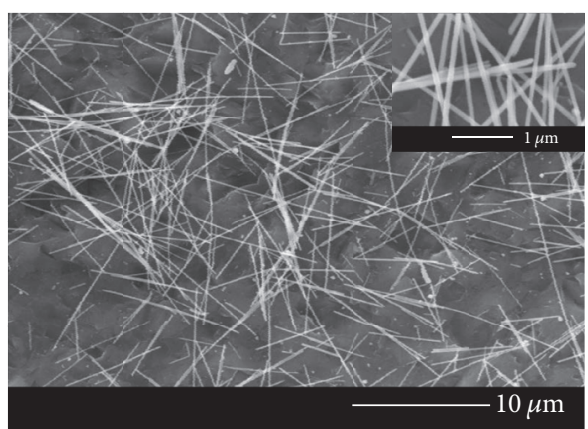

(b)

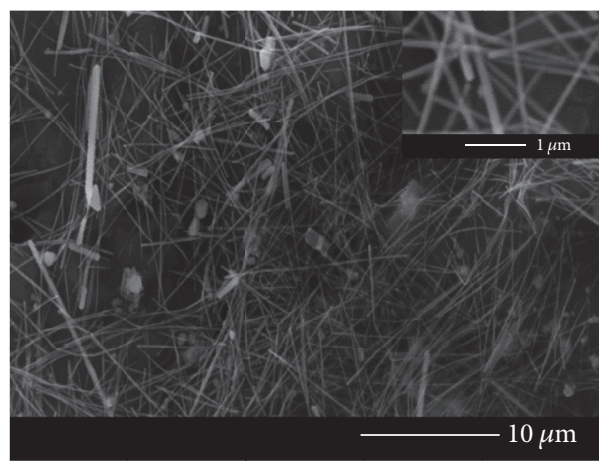

(c)

FIGURE 4: SEM images of Ag products formed by electroless deposition in hot ethylene glycol $\left(160^{\circ} \mathrm{C}\right)$ using increasing PVP molecular weight of (a) 10,000, (b) 55,000, and (c) 360,000 at PVP to $\mathrm{AgNO}_{3}$ molar ratio of 3.

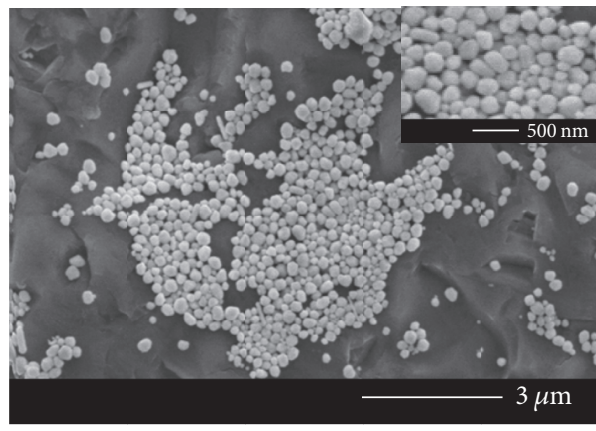

(a)

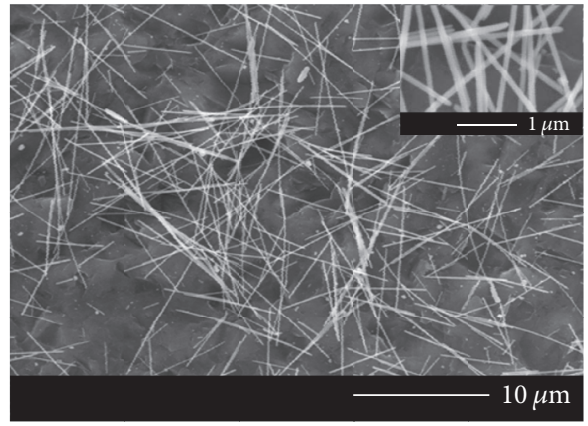

(b)

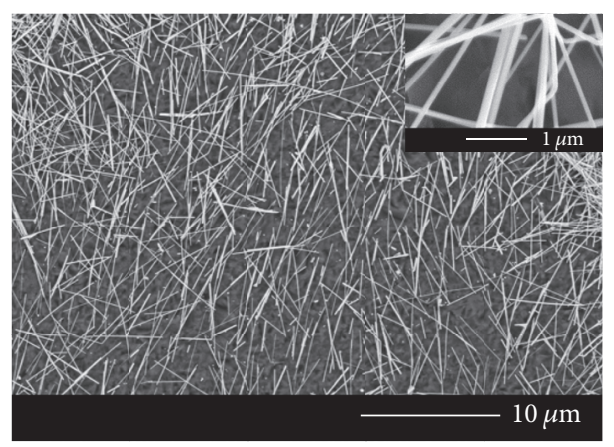

(c)

FIGURE 5: SEM images of Ag products obtained during electroless deposition in hot ethylene glycol at (a) 120 , (b) 160 , and (c) $180^{\circ} \mathrm{C}$ using PVP MW $=55,000$ and PVP to Ag ratio of 3. 


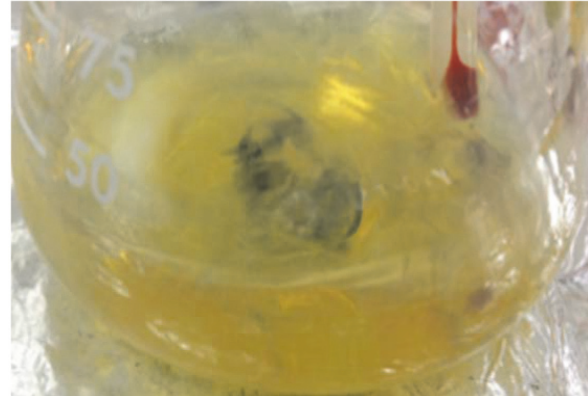

(a)

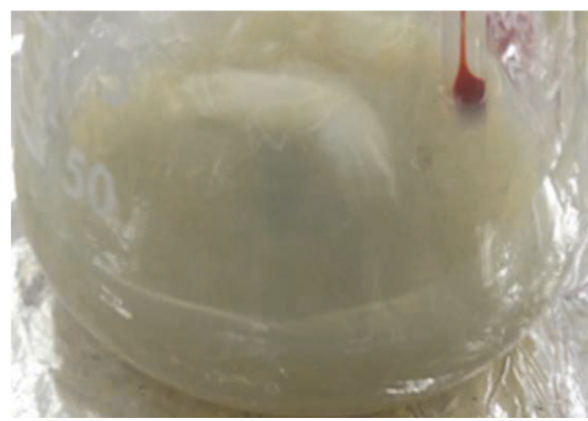

(b)

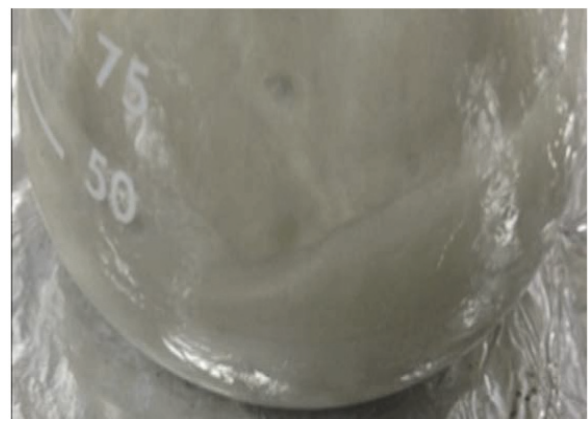

(c)

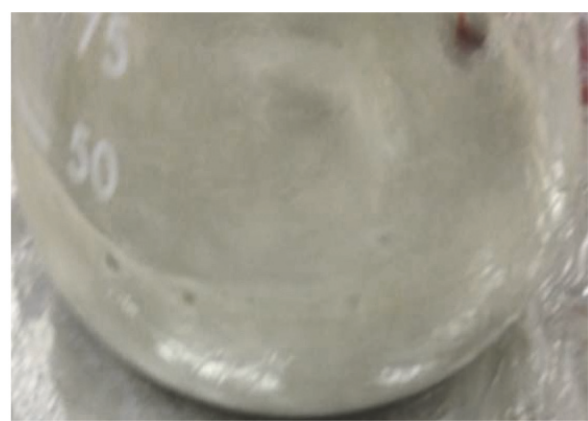

(d)

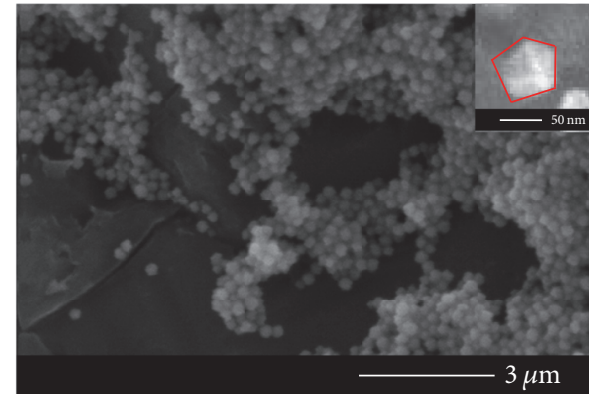

(a)i

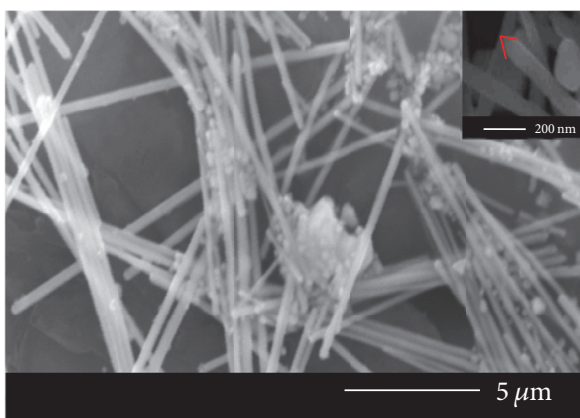

(b)i

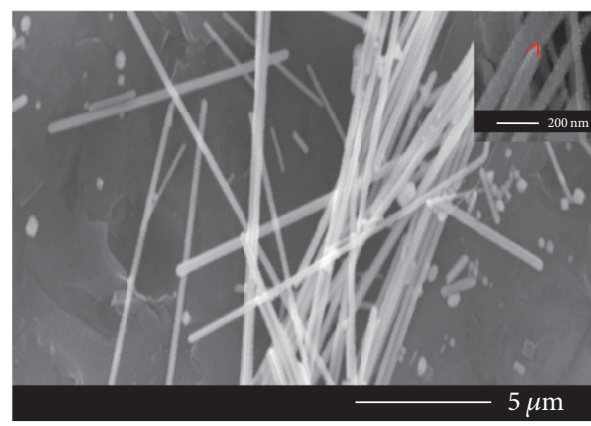

(c)i

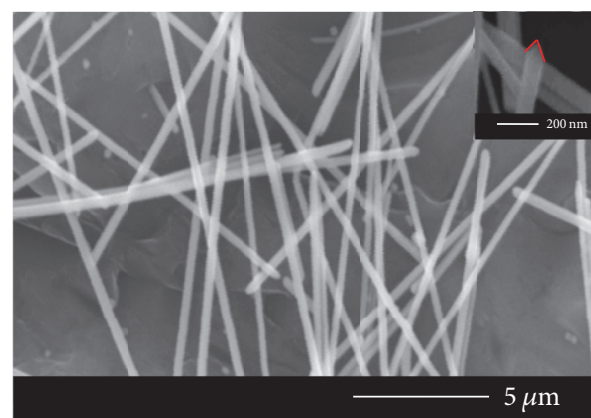

(d)i

Figure 6: Optical and SEM images of the Ag products formed after (a) 5, (b) 15, (c) 30, and (d) 60 min, reaction in hot ethylene glycol at $160^{\circ} \mathrm{C}$ using PVP $(\mathrm{MW}=55,000)$ to $\mathrm{Ag} \mathrm{NO}_{3}$ molar ratio of 3 . The inset at (a)i is a pentagonal multiply-twinned particle formed at the initial stage of the reaction. The pointed ends of the nanowires shown in the insets of $(\mathrm{b}-\mathrm{d}) \mathrm{i}$ suggest that twinning has occurred and that the nanowires may have grown from MTPs.

3.4. Growth Mechanism of Ag Nanowires by Electroless Deposition in Hot Ethylene Glycol. Figure 6 is the Ag products produced at increasing reaction time during electroless deposition using PVP $(\mathrm{MW}=55,000)$ to $\mathrm{AgNO}_{3}$ molar ratio of
3 at $160^{\circ} \mathrm{C}$. The precursor injection rate was set at $1 \mathrm{ml} / \mathrm{min}$. At the start of the reaction, the ethylene glycol (EG) solution turned from clear to yellow upon the simultaneous injection of $\mathrm{AgNO}_{3} / \mathrm{EG}$ and PVP/EG solutions as seen in Figure 6(a). 
This indicates the reduction of $\mathrm{Ag}^{+}$ions to atoms [38, 42]. As the reaction proceed to about $5 \mathrm{~min}$, enough $\mathrm{Ag}$ atoms were present in the solution to form nanoparticles as seen in the SEM image in Figure 6(a)i. Decahedral fivefold twinned particles or MTPs [inset in Figure 6(a)i] were present in the solution and possibly served as nuclei for the growth of nanowires. During the nucleation stage, the presence of PVP also prevents agglomeration of Ag nuclei through chemical adsorption on their surface, limiting their size in nanoscale [29, 30, 34, 36-40].

When the reaction was continued to about $15 \mathrm{~min}$, the yellow Ag-PVP-EG solution turned turbid grey as in Figure 6(b). This indicates growth of Ag particles to nanowires with lengths in the range of $2-5 \mu \mathrm{m}$. High-resolution SEM image in the inset of Figure 6(b)i shows the pointed crosssection of the Ag nanowire, which is due to the decahedral shape of the Ag nucleus. This suggests that the Ag nuclei obtained at the early stage of reaction indeed possess a multiply-twinned structure, which is consistent with other results obtained in this study and what have been reported in literature $[29,30,34,36-40]$.

At $30 \mathrm{~min}$ reaction time, the number of particles had decreased and nanowires were more apparent as seen in Figure 6(c)i. The disappearance of the Ag particles has been attributed to Ostwald ripening $[42,43]$, wherein small and unstable particles dissolved in the solution to provide additional Ag source for further nanowire growth. Compared to the nanowires collected after $15 \mathrm{~min}$, the nanowire diameter remained almost constant, indicating anisotropic growth. The measured average length was increased from 13.4 to $18.7 \mu \mathrm{m}$. After $60 \mathrm{~min}$, the solution turned dirty white, which implies the precipitation of high aspect ratio Ag nanowires [38-43]. Very few particles were observed, suggesting that most of the Ag nuclei have grown into nanowires and all other small particles were dissolved in the solution for nanowire growth.

Figure 7 illustrates the growth mechanism of $\mathrm{Ag}$ nanowires by electroless deposition in ethylene glycol using PVP as a surfactant. It was suggested that different Ag crystalline particles such as single crystal, cuboctahedral, and multiply-twinned (fivefold twinning) can be formed in solution during the polyol process [38-43]. However, at a high temperature of $160^{\circ} \mathrm{C}$, the large thermal energy promotes the formation of multiply-twinned crystals, which has a decahedral shape with a fivefold symmetry. As Ag nuclei are produced at the beginning of the reaction, they possibly assume a multiply-twinned structure, which are bound by the low energy $\{111\}$ facets. Anisotropic growth is then realized by the selective adsorption of PVP on the $\{100\}$ side facets of the Ag multiply-twinned crystals [29, 30, 34, 36-43]. PVP then passivates these side surfaces, slowing down Ag deposition on these sites. These leave the $\{111\}$ facets open for preferential deposition of Ag atoms, which lead to the one-directional growth of the Ag nuclei. Consequently, high aspect ratio $\mathrm{Ag}$ nanowires are produced.
TEM images and selected area electron diffraction of the $\mathrm{Ag}$ nanowire synthesized at $160^{\circ} \mathrm{C}$ using PVP $\mathrm{MW}=55,000$ at a molar ratio of 3 are shown in Figure 8. As observed in Figure $8(\mathrm{a})$, a thin amorphous layer of about $5.3 \mathrm{~nm}$ in thickness was present on the side facet of Ag nanowire. This passivating layer is possibly PVP as indicated by the difference in the contrast of this layer from the metallic nanowire. The TEM image in Figure 8(b) shows the pointed end of the Ag nanowire, which is characteristic of nanowires grown from multiply-twinned nuclei [29, 30, 34, 36-40]. The facets are possibly $\{111\}$, where Ag deposition occurs as illustrated in the schematic in Figure 7. Consequently, growth occurs along the $\langle 110\rangle$ direction, which is parallel to the nanowire length. Selected area electron diffraction (SAED) at the center of the Ag nanowire shows a spot diffraction pattern, indicating high crystallinity of the nanowire (Figure $8(\mathrm{c})$ ). The spot pattern was indexed to metallic Ag, which agrees with the XRD result in Figure 3. In addition, the growth direction of the nanowire was confirmed by measuring the angle between the (111) plane and the longitudinal axis. The measured value is about $35.8^{\circ}$. This value is close to the theoretical angle between (111) and (110) planes, which is $35.3^{\circ}$. Therefore, it can be inferred that the growth direction of the Ag nanowire is along the $\langle 110\rangle$ direction [29, 30, 34, 36-43].

Figure 9 shows the FTIR spectra of PVP-passivated Ag nanowires (ethanol) in comparison with pure PVP ( $\mathrm{MW}=$ $55,000)$. The absorption peak located at around $1,293 \mathrm{~cm}^{-1}$ can be assigned to the stretching vibration of $-\mathrm{C}-\mathrm{N}-$. The peaks at 1,655 and $2,957 \mathrm{~cm}^{-1}$ are due to $-\mathrm{C}=\mathrm{O}$ (carbonyl group) and $-\mathrm{C}-\mathrm{H}$ stretching vibrations, respectively. In addition, there is a broad peak located at around $3,417 \mathrm{~cm}^{-1}$, which can be assigned to the $\mathrm{O}-\mathrm{H}$ stretching vibration, indicating the presence of hydroxyl groups. The absorption peaks located at around $1,646 \mathrm{~cm}^{-1}$ can be assigned to the stretching vibration of $-\mathrm{C}=\mathrm{O}$. A red shift from 1,655 to $1,646 \mathrm{~cm}^{-1}$ was observed for the carbonyl absorption peaks of Ag nanowire/PVP compared with pure PVP. The carbonyl group of PVP may have gotten a part of the electrons of Ag nanowires resulting in an adsorption interaction between the two [44].

3.5. Fabrication of Ag Nanowires Transparent Conducting Electrode. Figure 10 shows the optical and electrical properties of the Ag nanowire flexible transparent conducting electrode at increasing nanowire density. The Ag nanowires were dispersed in ethanol. At $0.06 \mathrm{mg} / \mathrm{cm}^{2}$, the sheet resistance was $187.3 \Omega / \mathrm{sq}$ at a transmittance of $85.1 \%$ in the $550 \mathrm{~nm}$ wavelength. Increasing the Ag nanowire density to $0.18 \mathrm{mg} / \mathrm{cm}^{2}$ resulted in a decrease in both the sheet resistance $(44.2 \Omega / \mathrm{sq})$ and optical transmittance (72.3\%). A sheet resistance as low as $4.6 \Omega / \mathrm{sq}\left(53.1 \%\right.$ transmittance) was achieved at $0.30 \mathrm{mg} / \mathrm{cm}^{2}$. These values are comparable to the values reported for ITO [3-7]. Remarkably, the excellent sheet resistance was attained by the as-prepared Ag nanowires without any heat treatment. 

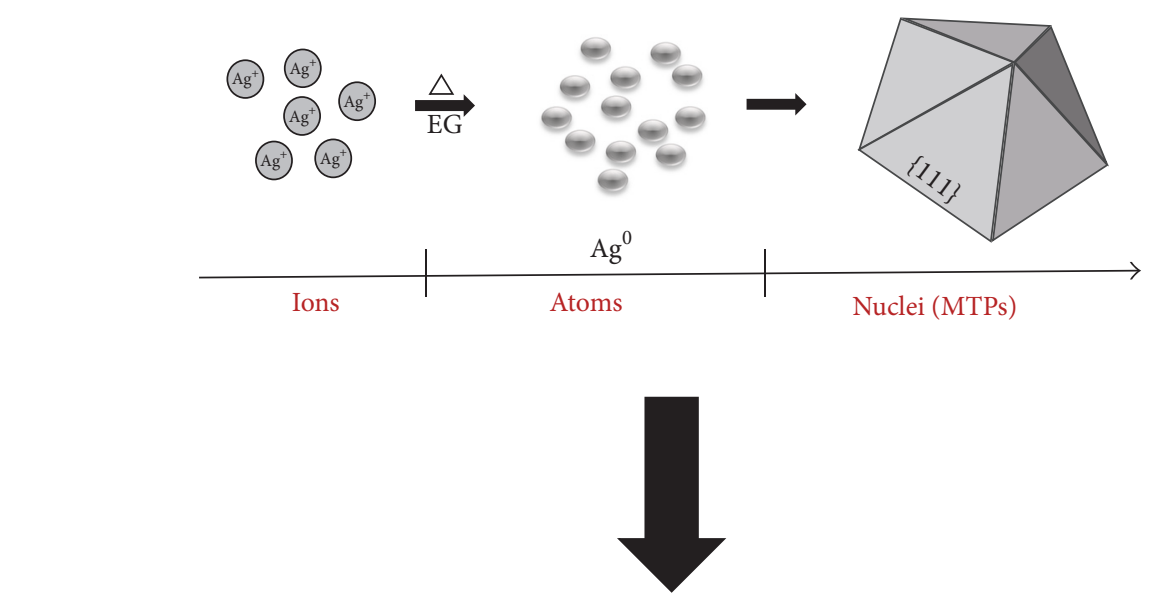

\section{Step 2: preferential growth}

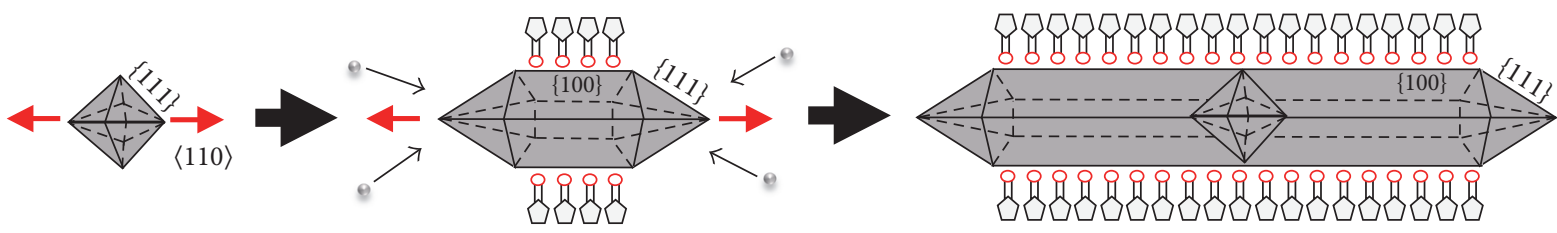

\begin{tabular}{c|c|c} 
& & \\
\hline $\begin{array}{c}\text { Fivefold twinned } \\
\text { particle }\end{array}$ & $\begin{array}{c}\text { Selective capping of PVP on }\{100\} \\
\text { facets and preferential deposition of } \\
\text { Ag atoms on }\{111\} \text { facets }\end{array}$ & $\begin{array}{c}\text { Continued growth in one direction } \\
\text { until all reagents are exhausted }\end{array}$
\end{tabular}

8 -PVP
-Ag atom

FIGURE 7: Schematic illustration of the growth mechanism of Ag nanowires by electroless deposition in ethylene glycol, in the presence of $\mathrm{PVP}$ as protective and structure-directing agent.

However, as a result of increasing the Ag nanowires density, the fabricated electrodes become very hazy.

One problem with the use of ethanol as a solvent is poor adhesion of the Ag nanowires on the substrates, which makes them prone to peeling and scratching. In order to address this problem, an ink solution was formulated in order to add a protective layer on the Ag nanowire film at the same time and provide better uniformity during the coating process [45]. For a nanowire density of $0.12 \mathrm{mg} / \mathrm{cm}^{2}$, the transmittance changed from $79.6 \%$ (ethanol) to $75.0 \%$ (ink formulation). The decrease in optical transmittance is probably due to the absorbance by the nitrocellulose film. Then again, no visible peeling was observed after tape test was performed as seen in Figures 11(a)-11(b). No significant change in the 


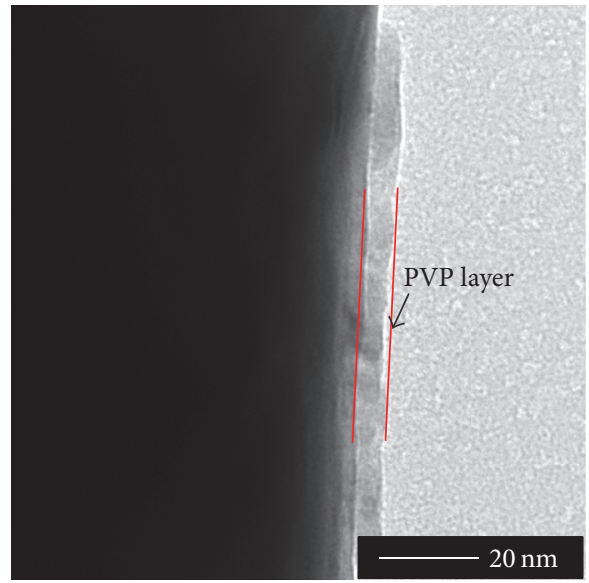

(a)

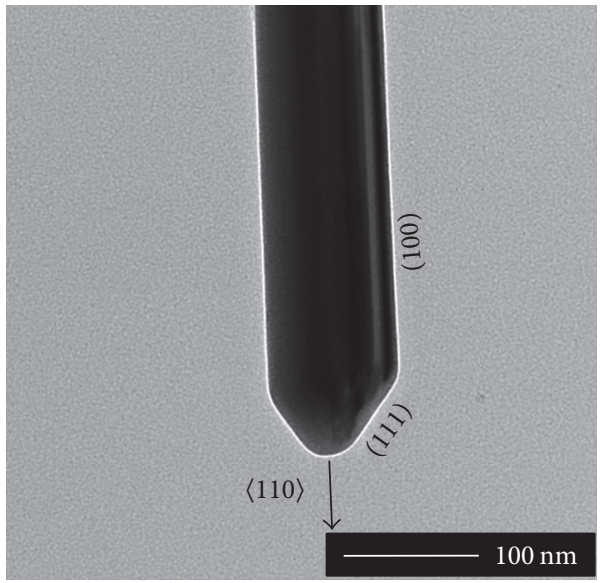

(b)

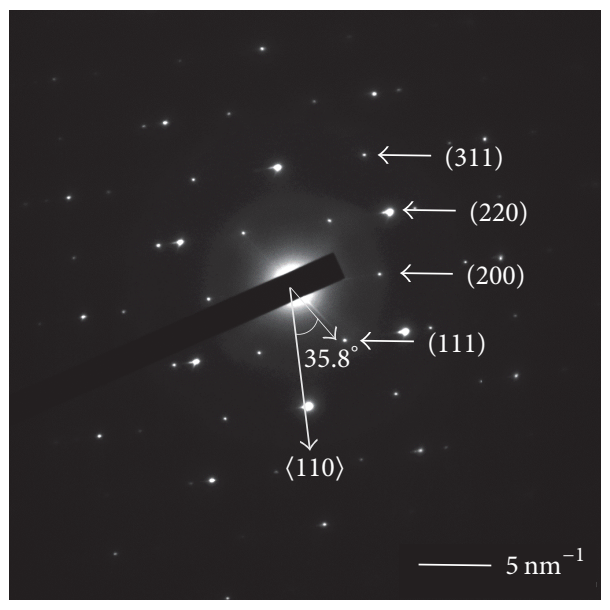

(c)

FIGURE 8: TEM images Ag nanowires showing (a) the presence of PVP on the side facet, (b) growth direction of the nanowires, and (c) selected area electron diffraction of the nanowire.

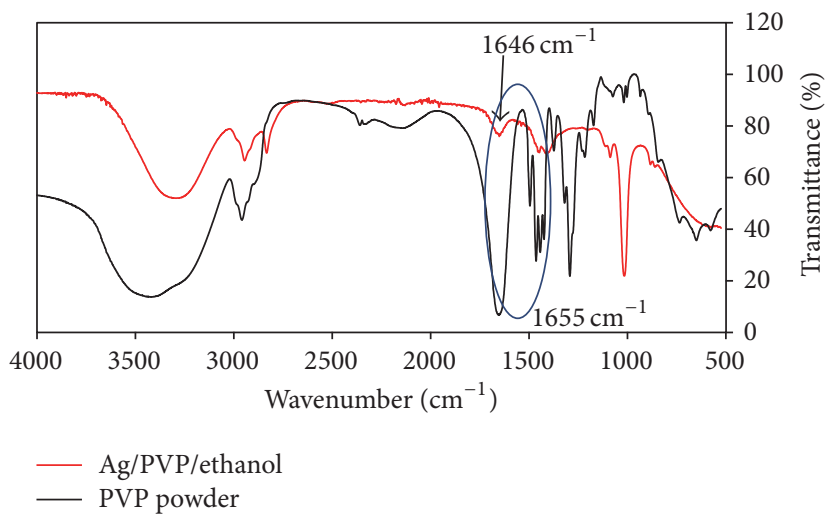

FIGURE 9: FTIR spectra of Ag nanowire/PVP in ethanol sample and pure PVP (MW =55,000). 


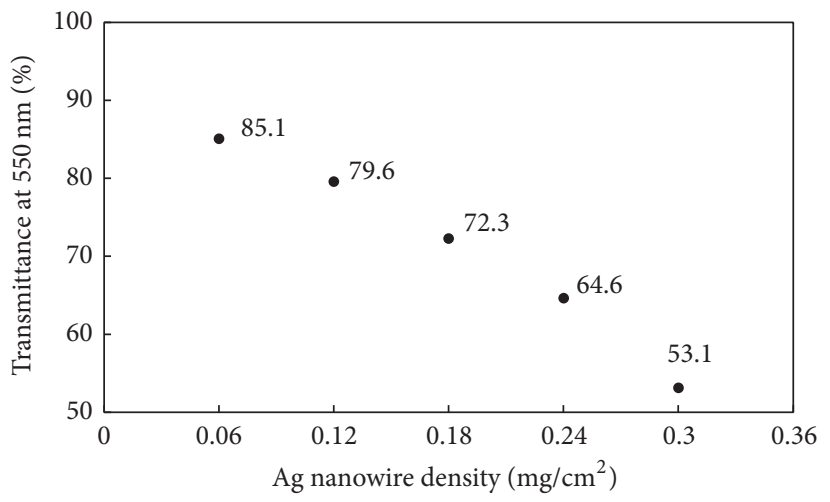

(a)

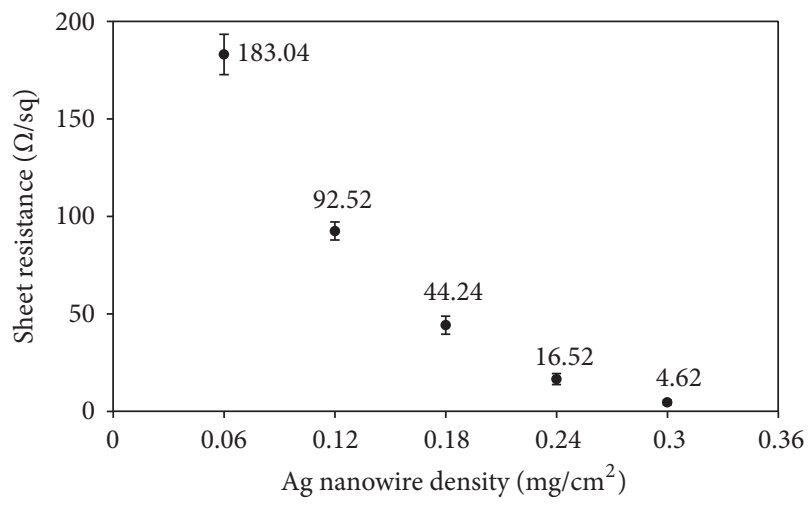

(b)

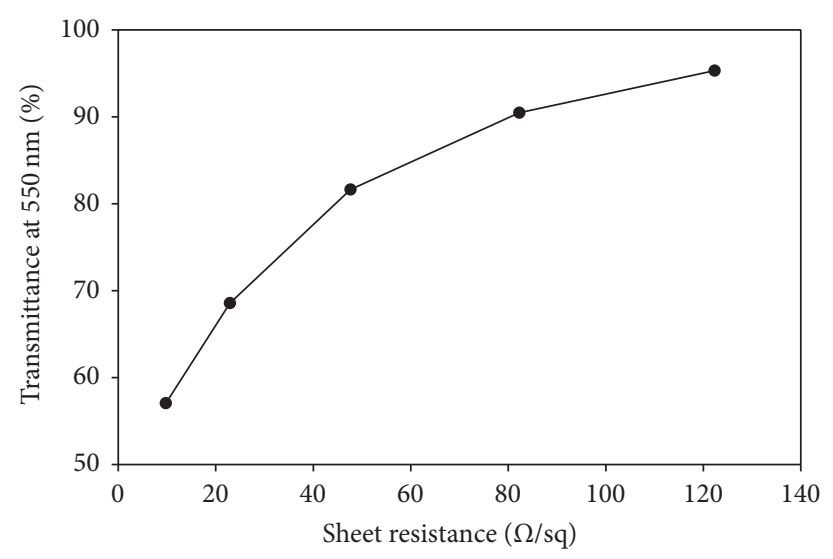

(c)

FIGURE 10: (a) Transmittance at $550 \mathrm{~nm}$ wavelength and (b) sheet resistance as a function of the Ag nanowire density for electrodes fabricated by Meyer rod coating on polymer substrates. (c) Plot of sheet resistance versus transmittance values. The Ag nanowires were dispersed in ethanol.

sheet resistance was also determined, suggesting that the nitrocellulose effectively acted as a protective layer during the coating process.

To test the stability of the Ag nanowires electrodes under bending, an electrode was bent for 100 cycles and the change in resistance $\left(R / R_{o}\right)$ was measured for each cycle where $R$ is the measured resistance after bending and $R_{o}$ is the initial resistance value (Figure 11(c)). It is notable that the $\mathrm{Ag}$ nanowires film showed an $R / R_{o}$ value of $<1.05$ even after bending a number of times, revealing a very high tolerance to bending, compared to ITO films which can fail abruptly after the application of tensile stress [38].

The charge carrying capacity of an Ag nanowire flexible transparent electrode with a sheet resistance of $84.0 \Omega / \mathrm{sq}$ at a transmittance of $80.0 \%$ was demonstrated in Figure 12. The electrode was connected in a series with a $5 \mathrm{~mA}$ LED, which was successfully lit after the application of $5 \mathrm{~V}$. The LED was observed to light up even after bending showing the potential of Ag nanowire transparent electrodes in flexible electronic device applications (Figure 12(b)).

\section{Conclusion}

Ultralong Ag nanowires were prepared by electroless deposition in hot ethylene glycol $\left(160^{\circ} \mathrm{C}\right)$ using PVP as structuredirecting agent. Both dimension and yield of $\mathrm{Ag}$ nanowires were affected to some degree by the amount and molecular weight of PVP in the solution. Generally, high aspect ratio $\mathrm{Ag}$ nanowires can be obtained at higher molecular weight and concentration of PVP. In addition, elevated temperature promotes the formation of $\mathrm{Ag}$ nanowires. Multiplytwinned Ag particles, which act as seeds for the growth of nanowires, are more easily formed due to the high thermal energy available at elevated temperatures. Without any harsh posttreatment, that is, annealing, Ag nanowire flexible transparent conducting electrodes achieve a sheet resistance in the range of $92.5-16.5 \Omega / \mathrm{sq}$ for optical transmittance values of $79.6-64.6 \%$.

\section{Conflicts of Interest}

The authors declare that they do not have any conflicts of interest. 


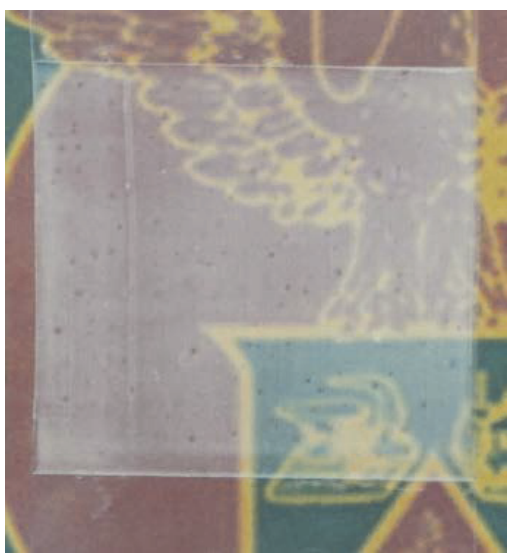

(a)

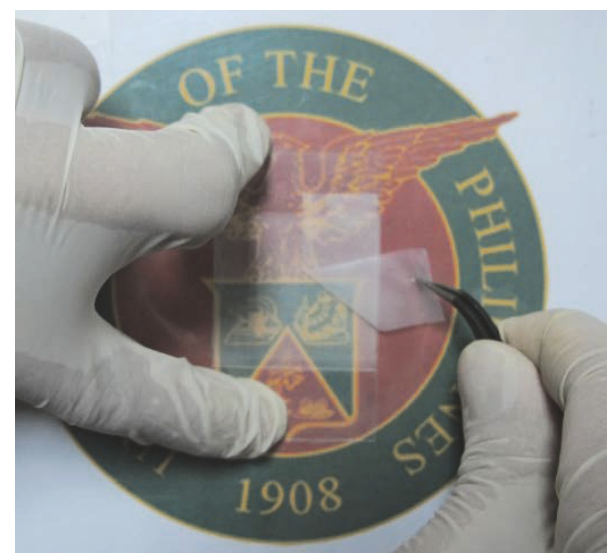

(b)

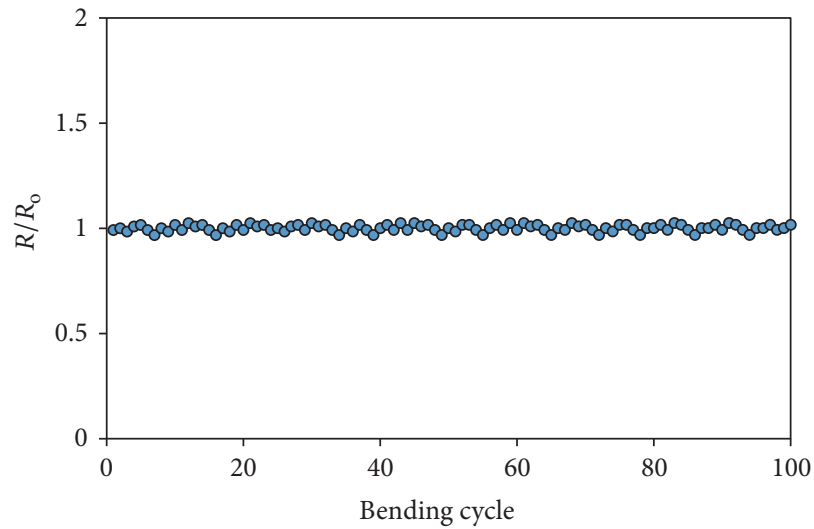

(c)

FIGURE 11: Images of a polymer substrate coated with the Ag nanowires/ink formulation (a) before and (b) after tape test. (c) Plot of the change in resistance $\left(R / R_{o}\right)$ as a function of bending cycles for an Ag nanowire/ink formulation on $2 \mathrm{~cm} \times 3 \mathrm{~cm}$ polymer electrode after bending 100 times.

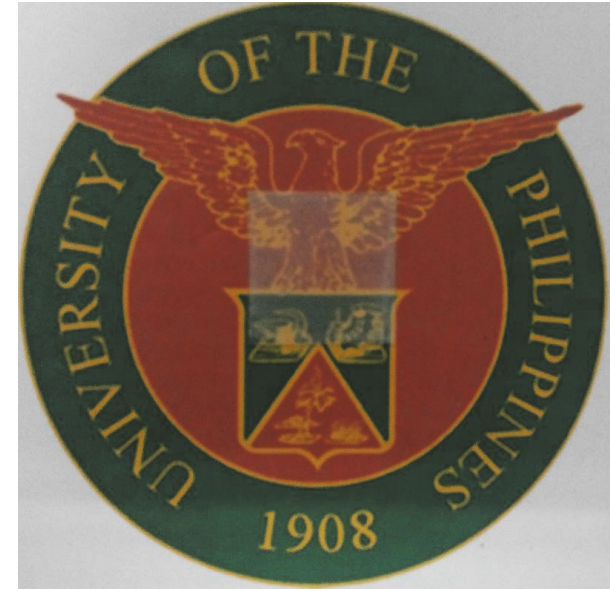

(a)

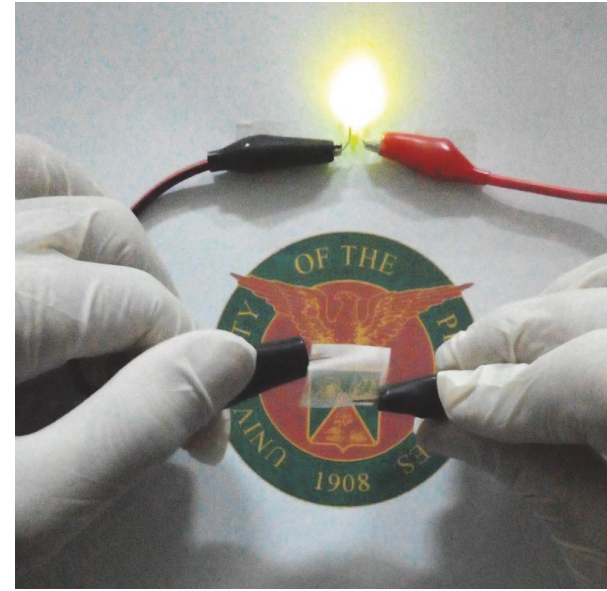

(b)

Figure 12: (a) Image of a flexible transparent electrode fabricated by Meyer rod coating $0.12 \mathrm{mg} / \mathrm{cm}^{2}$ of washed Ag nanowires on a cellulose acetate substrate. The electrode has a sheet resistance of $84.0 \Omega /$ sq at an optical transmittance of $80.0 \%$. (b) Demonstration of the flexibility and the charge carrying capacity of the electrode in a series connection with $5 \mathrm{~V}$ LED. 


\section{Acknowledgments}

The authors wish to thank the Department of Science and Technology through the Philippine Council for Industry Energy and Philippine Council for Industry, Energy, and Emerging Technology Research and Development (DOSTPCIEERD) under the research projects entitled "Synthesis of Metal Nanowire and Their Application in Flexible Transparent Conducting Electrode" and "Up-Scale Synthesis of Metal Nanowires and Their Application in Transparent Metal Nanowire Touch Panel" for funding this study. The authors also wish to thank Mr. Luigi Dahonog for the assistance in the preparation of this manuscript.

\section{References}

[1] K. Ellmer, "Past achievements and future challenges in the development of optically transparent electrodes," Nature Photonics, vol. 6, no. 12, pp. 809-817, 2012.

[2] S. De, T. M. Higgins, P. E. Lyons et al., "Silver nanowire networks as flexible, transparent, conducting films: extremely high DC to optical conductivity ratios," ACS Nano, vol. 3, no. 7, pp. 1767$1774,2009$.

[3] V. Muramba, M. Mageto, F. Gaitho et al., "Structural and optical characterization of tin oxide codoped with aluminum and sulphur," American Journal of Materials Science, vol. 5, no. 2, pp. 23-30, 2015.

[4] Z. Y. Banyamin, P. J. Kelly, G. West, and J. Boardman, "Electrical and optical properties of fluorine doped tin oxide thin films prepared by magnetron sputtering," Coatings, vol. 4, no. 4, pp. 732-746, 2014.

[5] Y. Liu, Y. Li, and H. Zeng, "ZnO-based transparent conductive thin films: doping, performance, and processing," Journal of Nanomaterials, vol. 2013, Article ID 196521, 9 pages, 2013.

[6] B. Zhang, X. Dong, X. Xu, X. Wang, and J. Wu, "Electrical and optical properties of ITO and ITO: Zr transparent conducting films," Materials Science in Semiconductor Processing, vol. 10, no. 6, pp. 264-269, 2007.

[7] A. Kumar and C. Zhou, "The race to replace tin-doped indium oxide: which material will win?" ACS Nano, vol. 4, no. 1, pp. 11$14,2010$.

[8] T. Minami, "Transparent conducting oxide semiconductors for transparent electrodes," Semiconductor Science and Technology, vol. 20, no. 4, pp. S35-S44, 2005.

[9] B. G. Lewis and D. C. Paine, "Applications and processing of transparent conducting oxides," MRS Bulletin, vol. 25, no. 8, pp. 22-27, 2000.

[10] S. H. Mohamed, F. M. El-Hossary, G. A. Gamal, and M. M. Kahlid, "Properties of indium tin oxide thin films deposited on polymer substrates," Acta Physica Polonica A, vol. 115, no. 3, pp. 704-708, 2009.

[11] D. S. Hecht, L. Hu, and G. Irvin, "Emerging transparent electrodes based on thin films of carbon nanotubes, graphene, and metallic nanostructures," Advanced Materials, vol. 23, no. 13, pp. 1482-1513, 2011.

[12] H. C. Schniepp, K. N. Kudin, J.-L. Li et al., "Bending properties of single functionalized graphene sheets probed by atomic force microscopy," ACS Nano, vol. 2, no. 12, pp. 2577-2584, 2008.

[13] W. Hong, Y. Xu, G. Lu, C. Li, and G. Shi, "Transparent graphene/PEDOT-PSS composite films as counter electrodes of dye-sensitized solar cells," Electrochemistry Communications, vol. 10, no. 10, pp. 1555-1558, 2008.

[14] S. Iijima and T. Ichihashi, "Single-shell carbon nanotubes of 1nm diameter," Nature, vol. 363, no. 6430, pp. 603-605, 1993.

[15] S. Xie, W. Li, Z. Pan, B. Chang, and S. Lianfeng, "Mechanical and physical properties on carbon nanotube," Journal of Physics and Chemistry of Solids, vol. 61, no. 7, pp. 1153-1158, 2000.

[16] K. S. Novoselov, A. K. Geim, S. V. Morozov et al., "Electric field in atomically thin carbon films," Science, vol. 306, no. 5696, pp. 666-669, 2004.

[17] Z. C. Wu, Z. H. Chen, X. Du et al., "Transparent, conductive carbon nanotube films," Science, vol. 305, no. 5688, pp. $1273-$ $1276,2004$.

[18] H.-Z. Geng, K. K. Ki, P. S. Kang, S. L. Young, Y. Chang, and H. L. Young, "Effect of acid treatment on carbon nanotube-based flexible transparent conducting films," Journal of the American Chemical Society, vol. 129, no. 25, pp. 7758-7759, 2007.

[19] J. G. Tait, B. J. Worfolk, S. A. Maloney et al., "Spray coated highconductivity PEDOT:PSS transparent electrodes for stretchable and mechanically-robust organic solar cells," Solar Energy Materials and Solar Cells, vol. 110, pp. 98-106, 2013.

[20] J. Zou, H.-L. Yip, S. K. Hau, and A. K.-Y. Jen, "Metal grid/conducting polymer hybrid transparent electrode for inverted polymer solar cells," Applied Physics Letters, vol. 96, no. 20, Article ID 203301, pp. 203-301, 2010.

[21] J. Van De Groep, P. Spinelli, and A. Polman, "Transparent conducting silver nanowire networks," Nano Letters, vol. 12, no. 6, pp. 3138-3144, 2012.

[22] A. R. Rathmell and B. J. Wiley, "The synthesis and coating of long, thin copper nanowires to make flexible, transparent conducting films on plastic substrates," Advanced Materials, vol. 23, no. 41, pp. 4798-4803, 2011.

[23] A. R. Rathmell, S. M. Bergin, Y.-L. Hua, Z.-Y. Li, and B. J. Wiley, "The growth mechanism of copper nanowires and their properties in flexible, transparent conducting films," Advanced Materials, vol. 22, no. 32, pp. 3558-3563, 2010.

[24] L. Hu, H. S. Kim, J.-Y. Lee, P. Peumans, and Y. Cui, "Scalable coating and properties of transparent, flexible, silver nanowire electrodes," ACS Nano, vol. 4, no. 5, pp. 2955-2963, 2010.

[25] P.-C. Hsu, S. Wang, H. Wu et al., "Performance enhancement of metal nanowire transparent conducting electrodes by mesoscale metal wires," Nature Communications, vol. 4, article 2522, 2013.

[26] J. Lee, S. T. Connor, Y. Cui, and P. Peumans, "Solution-processed metal nanowire mesh transparent electrodes," Nano Letters, vol. 8, no. 2, pp. 689-692, 2008.

[27] Z. Yang, H. Qian, H. Chen, and J. N. Anker, "One-pot hydrothermal synthesis of silver nanowires via citrate reduction," Journal of Colloid and Interface Science, vol. 352, no. 2, pp. 285-291, 2010.

[28] M. Tsuji, K. Matsumoto, P. Jiang, R. Matsuo, X.-L. Tang, and K. S. N. Kamarudin, "Roles of Pt seeds and chloride anions in the preparation of silver nanorods and nanowires by microwavepolyol method," Colloids and Surfaces A: Physicochemical and Engineering Aspects, vol. 316, no. 1-3, pp. 266-277, 2008.

[29] B. Wiley, Y. Sun, and Y. Xia, "Synthesis of silver nanostructures with controlled shapes and properties," Accounts of Chemical Research, vol. 40, no. 10, pp. 1067-1076, 2007.

[30] Y. Sun and Y. Xia, "Large-scale synthesis of uniform silver nanowires through a soft, self-seeding, polyol process," Advanced Materials, vol. 14, no. 11, pp. 833-837, 2002. 
[31] A. R. Madaria, A. Kumar, F. N. Ishikawa, and C. Zhou, "Uniform, highly conductive, and patterned transparent films of a percolating silver nanowire network on rigid and flexible substrates using a dry transfer technique," Nano Research, vol. 3, no. 8, pp. 564-573, 2010.

[32] N. E. Hjerrild, D. C. J. Neo, A. Kasdi, H. E. Assender, J. H. Warner, and A. A. R. Watt, "Transfer printed silver nanowire transparent conductors for $\mathrm{PbS}-\mathrm{ZnO}$ heterojunction quantum dot solar cells," ACS Applied Materials and Interfaces, vol. 7, no. 12, pp. 6417-6421, 2015.

[33] C.-H. Liu and X. Yu, "Silver nanowire-based transparent, flexible, and conductive thin film," Nanoscale Research Letters, vol. 6, no. 75, 2011.

[34] N. De Guzman and M. D. Balela, "Formation of silver nanowires in ethylene glycol for transparent conducting electrodes," in Advanced Materials, Structures and Mechanical Engineering, Chapter 75, pp. 351-354, 2016.

[35] N. De Guzman and M. D. Balela, " $\mathrm{CuCl}_{2}$-mediated synthesis of silver nanowires for flexible transparent conducting films," in Proceedings of the 4th International Conference on Engineering and Innovative Materials, ICEIM '15, vol. 27, article 03007, September 2015.

[36] V. Scardaci, R. Coull, P. E. Lyons, D. Rickard, and J. N. Coleman, "Spray deposition of highly transparent, low-resistance networks of silver nanowires over large areas," Small, vol. 7, no. 18, pp. 2621-2628, 2011.

[37] S. Nam, M. Song, D.-H. Kim et al., "Ultrasmooth, extremely deformable and shape recoverable Ag nanowire embedded transparent electrode," Scientific Reports, vol. 4, article 4788, 2014.

[38] K. E. Korte, S. E. Skrabalak, and Y. Xia, "Rapid synthesis of silver nanowires through a $\mathrm{CuCl}$ - or $\mathrm{CuCl}_{2}$-mediated polyol process," Journal of Materials Chemistry, vol. 18, no. 4, pp. 437-441, 2008.

[39] K. Peppler and J. Janek, "Template assisted solid state electrochemical growth of silver micro- and nanowires," Electrochimica Acta, vol. 53, no. 2, pp. 319-323, 2007.

[40] T. Tetsumoto, Y. Gotoh, and T. Ishiwatari, "Mechanistic studies on the formation of silver nanowires by a hydrothermal method," Journal of Colloid and Interface Science, vol. 362, no. 2, pp. 267-273, 2011.

[41] F. Fievet, J. P. Lagier, B. Blin, B. Beaudoin, and M. Figlarz, "Homogeneous and heterogeneous nucleations in the polyol process for the preparation of micron and submicron size metal particles," Solid State Ionics, vol. 32-33, no. 1, pp. 198-205, 1989.

[42] S. E. Skrabalak, B. J. Wiley, M. Kim, E. V. Formo, and Y. Xia, "On the polyol synthesis of silver nanostructures: glycolaldehyde as a reducing agent," Nano Letters, vol. 8, no. 7, pp. 2077-2081, 2008.

[43] H. Mao, J. Feng, X. Ma, C. Wu, and X. Zhao, "One-dimensional silver nanowires synthesized by self-seeding polyol process," Journal of Nanoparticle Research, vol. 14, no. 6, article 887, 2012.

[44] R. R. Lunt and V. Bulovic, "Transparent, near-infrared organic photovoltaic solar cells for window and energy-scavenging applications," Applied Physics Letters, vol. 98, no. 11, Article ID 113305, 2011.

[45] Y. Ko, S. K. Song, N. H. Kim, and S. T. Chang, "Highly transparent and stretchable conductors based on a directional arrangement of silver nanowires by a microliter-scale solution process," Langmuir, vol. 32, no. 1, pp. 366-373, 2016. 

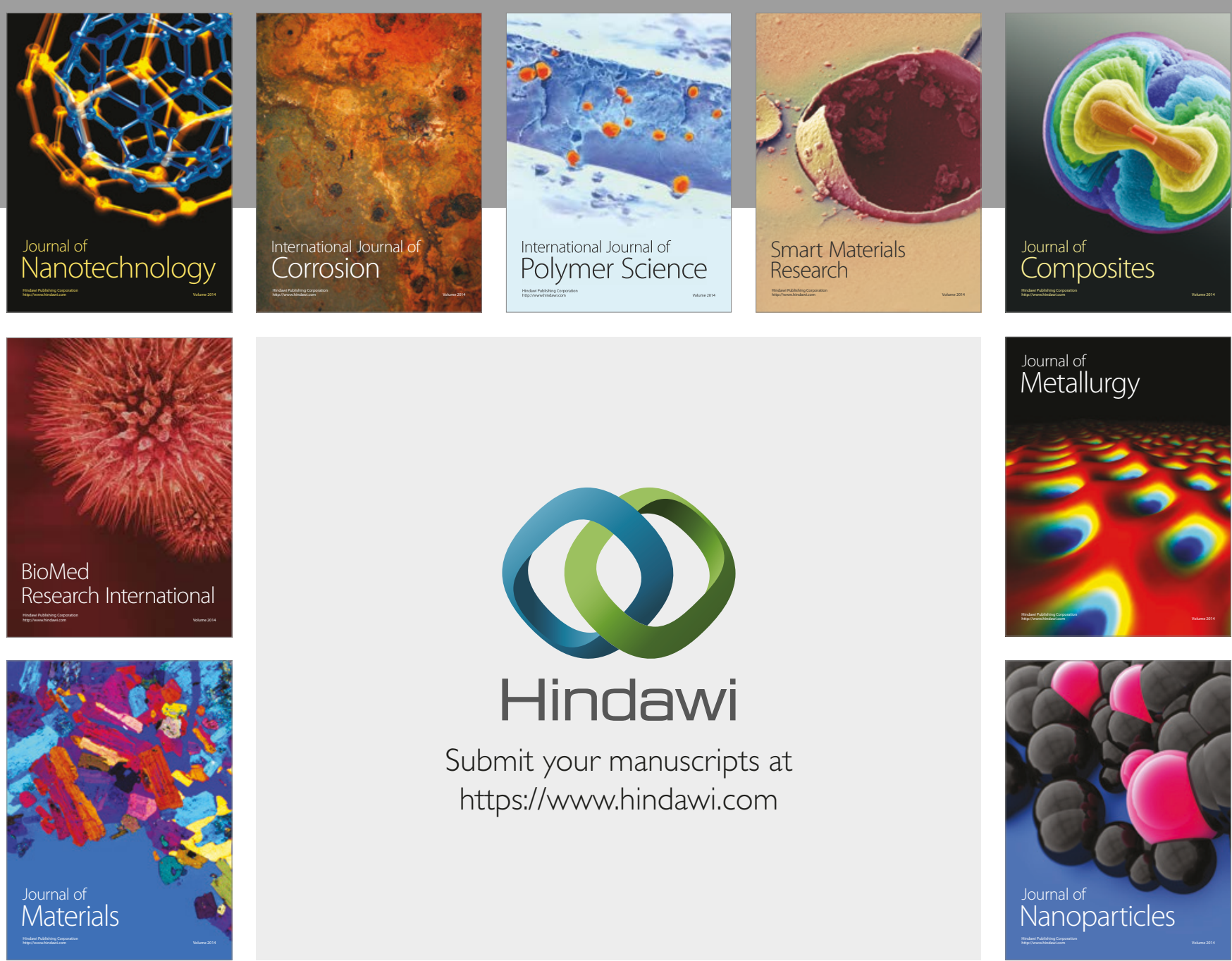

\section{Hindawi}

Submit your manuscripts at

https://www.hindawi.com
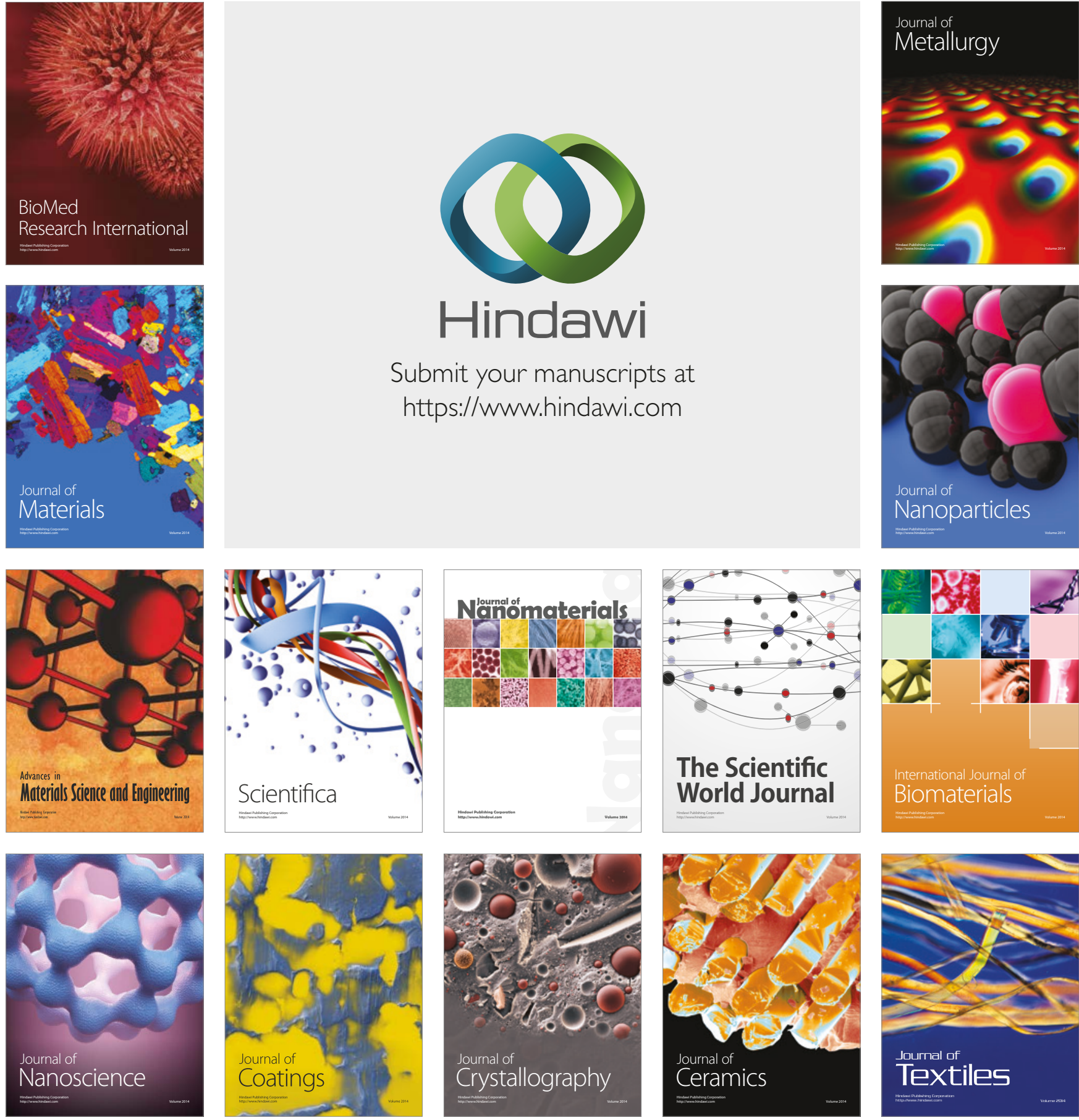

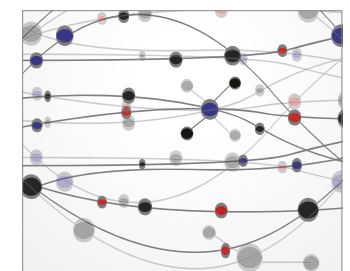

The Scientific World Journal
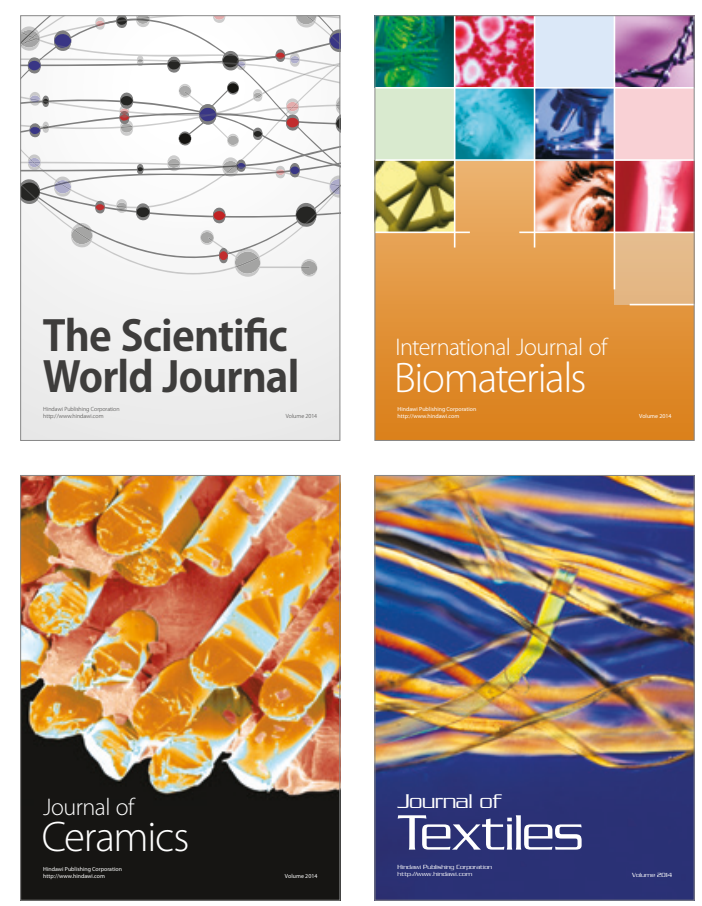